Research articles

\title{
Synthesis and characterization of magnetic-montmorillonite and magnetic- organo-montmorillonite: Surface sites involved on cobalt sorption
}

\author{
Facundo Barraquéa, Maria L. Montes ${ }^{\mathrm{b}, *}$, Mariela A. Fernández ${ }^{\mathrm{a}}$, Roberto C. Mercader ${ }^{\mathrm{b}}$, \\ Roberto J. Candal ${ }^{\mathrm{c}}$, Rosa M. Torres Sánchez ${ }^{\mathrm{a}}$

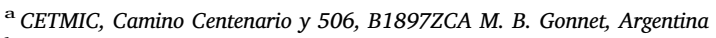 \\ ${ }^{\mathrm{b}}$ IFLP, Instituto de Física La Plata - CONICET CCT-La Plata, Departamento de Física, Facultad de Ciencias Exactas, Universidad Nacional de La Plata, La Plata, Argentina \\ ${ }^{\mathrm{c}}$ Instituto de Investigación e Ingeniería Ambiental, CONICET, Universidad Nacional de San Martín, Av. 25 de Mayo y Francia, San Martin 1650, Argentina
}

\section{A R T I C L E IN F O}

\section{Keywords:}

Magnetic composite synthesis

Magnetite

Montmorillonite

Organo-montmorillonite cobalt sorption

\begin{abstract}
A B S T R A C T
Montmorillonite magnetic-clay nanoparticles (MtMag) and its exchanged product with hexadecyltrimethylammonium (O100MtMag) were synthetized by alkaline oxidation of ferrous sulfate, characterized by diverse techniques (XRD, Mössbauer spectroscopy, VSM, SEM, Zeta Potential, total specific surface area, TOC) and used as $\mathrm{Co}^{2+}$ sorbents. The magnetic characteristic of these materials allows them to be used in cases of decontamination of water polluted with dangerous materials, such as radioactive ones, reducing the risk to health due to indirect manipulation by means of external magnetic fields. For comparison, samples without magnetic material (O100Mt) and in absence of clay (Mag) were also synthetized. The synthesis of magnetic materials disclosed the presence of magnetite and goethite nanoparticles, while the saturation magnetization displayed by O100MtMag was higher than that obtained for MtMag, indicating the existence of a higher amount of magnetite particles in the first one. This suggests that O100MtMag could be manipulated easier than MtMag through external magnetic fields. Moreover, the surface electric charge of MtMag sample can be described as a mixture of Magnetite and montmorillonite, with ratios related to the surface of both components. $\mathrm{Co}^{2+}$ sorption $^{2}$ percentages, using an initial $\mathrm{Co}^{2+}$ concentration of $85 \mathrm{mg} / \mathrm{L}$, resulted similar for the different materials while the $\mathrm{Co}^{2+}$ sorption was ascribed to interactions with the montmorillonite interlayer and external surface. The current results indicate that $\mathrm{O} 100 \mathrm{MtMag}$ is a more appropriate material than MtMag for $\mathrm{Co}^{2+}$ removal by external magnets.
\end{abstract}

\section{Introduction}

In the last decades a significant interest has been devoted to search ecofriendly, sustainable and low-cost technologies for pollutants removal from wastewater. Among these, sorption has excelled as an effective and economical technique, generating the need to obtain new sorbent materials with higher retention capacity or different manipulation possibilities.

Magnetic nano-materials have attracted scientific interest due to its adsorbent ability and isolation capacity by application of external magnetic fields. These features allow them to be used in many applications. For example, in medicine, anticancer drugs are loaded with magnetic materials to be directed to particular sites thus reducing the dose required in several therapies and minimizing side-effects [1,2]; in effluent treatments, for the removal of dyes, heavy metals, and biologically active compounds with high separation efficiency and reusability [3-6], etc.

Moreover, montmorillonite (Mt) has been largely used as sorbent materials for a wide range of pollutants, like heavy metals [7-9] and organic compounds [10-13] because of its relatively large surface area, cation-exchange capacity (CEC), swell-ability, great abundance and low cost. One of the strategies to extend and/or enhance the montmorillonites adsorption spectrum of contaminants was to tailor the clay structures. Particularly, the attachment of long chain alkyl groups of quaternary amino compounds (QAC) to different clays generate the so called organoclays, which improves not only the adsorption of organic pollutants $[14,15]$ by increasing the number of non-polar sites thus generating more effective interactions with organic molecules, but also promotes a better separation of the suspension by increasing its particle size [16].

Combination of magnetic nanoparticles with clays has been applied even in enzymatic immobilization [17], as bactericide materials [18],

\footnotetext{
* Corresponding author.

E-mail address: 1montes@fisica.unlp.edu.ar (M.L. Montes).
} 
in catalytic activity $[19,20]$, environmental remediation and biocompatible materials [21-24].

Furthermore, the development of magnetic Mt or organo-Mt systems would allow to dangerous pollutant removal in continuous process, promoting the sorbent separation advantage by an external magnetic field and reducing the risk to health due to indirect manipulation.

There are several methods to synthesize $\mathrm{Fe}_{3} \mathrm{O}_{4}$ nanoparticles: oxidative hydrolysis of iron (II) sulfate in alkaline media, alkaline hydrolysis of iron (II) and iron (III) chloride solutions, controlled alkaline oxidation in nitrate presence and precipitation from iron (II) and iron (III) chloride solutions by hydrolysis of urea. Among them, the controlled alkaline oxidation of iron (II) sulfate produce high-size magnetite particles, with the advantage of being an easy, efficient, and economical preparation process [21,23,25-27].

In this work $\mathrm{Fe}_{3} \mathrm{O}_{4}$ nanoparticles have been synthesized by controlled alkaline oxidation of iron (II) sulfate in absence (Mag) and presence (MtMag) of montmorillonite clay. In addition, hexadecyltrimethylammonium bromide (HDTMABr) has been used to attain the organo-Mt (O100Mt) exchanged $100 \%$ of CEC and to further synthesize $\mathrm{Fe}_{3} \mathrm{O}_{4}$ nanoparticles in the sample (O100MtMag). A deep characterization of all these materials has been performed by X-ray diffraction (XRD), Mössbauer spectroscopy, vibrating sample magnetometer (VSM), scanning electron microscopy (SEM), and zeta potential determination.

Cobalt is a heavy metal that can be released for diverse industries, including the nuclear one. The development of sorbent materials to optimize the nuclear wastewater treatment is crucial for human health and environmental quality and the magnetic materials will allow reducing its manipulation, diminishing the radioactivity exposition and the health risk. With this fact in mind, the ability of the different synthetized materials was analyzed performing Co sorption experiments in batch condition, and determining the surface sites involved.

\section{Materials and methods}

The raw material, previously characterized, was commercial Argentine bentonite (Castiglioni Pes and Co.) from Río Negro Province. The chemical analysis performed on a sample of purified montmorillonite (Mt), yielded the structural formula [ $\left(\mathrm{Si}_{3.89} \mathrm{Al}_{0.11}\right)\left(\mathrm{Al}_{1.43} \mathrm{Fe}_{0.26}\right.$ $\left.\mathrm{Mg}_{0.30}\right) \mathrm{Na}_{0.30} \mathrm{Ca}_{0.09} \mathrm{~K}_{0.01}$, isoelectric point (IEPpH $=2.7$ ), external surface area (determined by $\mathrm{N}_{2}$ adsorption) of $34.0 \mathrm{~m}^{2} / \mathrm{g}$ [28] and cation exchange capacity (CEC) equal to $0.825 \mathrm{mmol} \mathrm{g}^{-1}$ [29].

The magnetic samples were synthesized using $\mathrm{KNO}_{3}$ and $\mathrm{KOH}(99 \%$ purity) purchased from Biopack and $\mathrm{Fe}\left(\mathrm{SO}_{4}\right) \cdot 7 \mathrm{H}_{2} \mathrm{O}$ (analytical degree) bought from Cicarelli Lab.

The hexadecyltrimethylammonium bromide (HDTMABr) ( $\geq 97 \%)$, $\mathrm{MW}=364.45 \mathrm{~g} / \mathrm{mol}$ and critical micelle concentrations (CMC), $0.9 \mathrm{mM}$ [30], was delivered by Fluka (Buchs, Switzerland) and used as received. $\mathrm{CoCl}_{2} \cdot 6 \mathrm{H}_{2} \mathrm{O}(99 \%)$ was provided by Sigma.

The procedure indicated previously by Gamba et al.[29] was carried out to obtain organic-montmorillonite. Briefly, an amount of the HDTMABr equivalent to $100 \%$ CEC value of Mt was dissolved in $1 \mathrm{~L}$ of distilled water and $15 \mathrm{~g}$ of Mt was slowly added and stirred (400 rpm) for $24 \mathrm{~h}$. The product attained was washed with distilled water to free them of bromide anions (tested by $\mathrm{AgNO}_{3}$ ), lyophilized, ground in an agate mortar and labeled as O100Mt.

The preparation of magnetic montmorillonite (MtMag) was performed following the method described by Bartonkova et al. [27]. Briefly, $25 \mathrm{~mL}$ of $\mathrm{FeSO}_{4} \cdot 7 \mathrm{H}_{2} \mathrm{O}(0.3 \mathrm{M})$ was added to an aqueous $\mathrm{Mt}$ suspension $\left(2.5 \mathrm{~g} / 425 \mathrm{~mL}\right.$ water). After stirring for $2 \mathrm{~h}, 25 \mathrm{~mL}$ of $\mathrm{KNO}_{3}$ $(0.49 \mathrm{M})$ and $25 \mathrm{~mL}$ of $\mathrm{KOH}(1.25 \mathrm{M})$ were added, and the temperature of the suspension was raised to $90{ }^{\circ} \mathrm{C}$. The magnetite formation was followed by the change of the color suspension to dark brown [31]. The dispersion was cooled at room temperature and washed twice with distilled water. The solid was recovered by magnetic separation and lyophilized.
Pure magnetic material (Mag) was also obtained by mixing the corresponding reagents and following the same procedure described previously without the clay mineral.

Organic-magnetic montmorillonite (O100MtMag) was obtained following the Bartonkova et al. [27] procedure using as starting clay material O100Mt sample.

In order to compare some MtMag sample properties, $1 \mathrm{~g}$ of mechanical mixture of Mt and Mag 70:30 (w/w) was dissolved in $100 \mathrm{~mL}$ $\mathrm{KCl} 10^{-3} \mathrm{M}$ stirred $10 \mathrm{~min}$ and used for XRD analysis and zeta potential determination.

X-ray diffraction (XRD) patterns were collected using a Philips PW 1710 diffractometer with $\mathrm{CuK}_{\alpha}$ radiation, operated at $40 \mathrm{kV}$ and $30 \mathrm{~mA}$, with counting time $10 \mathrm{~s} / \mathrm{step}$ and $0.02^{\circ}(2 \theta)$ step size. Samples were scanned on oriented samples maintained at constant relative humidity of 0.47 for $48 \mathrm{~h}$ in order to improve the precision of the peak values [32].

Mössbauer spectroscopy (MS) spectra of all materials were collected at RT using a constant-acceleration spectrometer in transmission geometry with a ${ }^{57} \mathrm{Co} / \mathrm{Rh}$ source (nominal activity $5 \mathrm{mCi}$ ) and a multichannel scaler of 512 channels. Velocity calibration was performed using a $12 \mu \mathrm{m}$ thick $\alpha$-Fe foil. Hyperfine parameters are referred to this standard. Mt Mössbauer spectrum was collected between -4.0 and $4.0 \mathrm{~mm} / \mathrm{s}$, due to the absence of magnetic compounds, while the magnetic samples spectra were measured from -11 to $11 \mathrm{~mm} / \mathrm{s}$. All the spectra were numerically analyzed using a computer code that takes into account hyperfine magnetic fields and quadrupole splitting distributions [33].

The high-field susceptibility $\left(\chi_{\text {hifi }}\right)$, saturation magnetization (Ms) and remnant magnetization $(\mathrm{Mr})$ were determined from the hysteresis loops acquired in a VSM magnetometer LakeShore 7404 using external magnetic fields between $-1.9 \mathrm{~T}$ and $1.9 \mathrm{~T}$. Samples were supported in a diamagnetic sample holder with negligible magnetic response.

Scanning electron microphotographs (SEM) were performed in a JEOL, JCM-6000 with combined energy dispersive X-ray spectroscopy (EDS) analyzer. Samples were fixed to $10 \mathrm{~mm}$ metal mounts using carbon tape, and spit coated with gold under vacuum in argon atmosphere.

Electrokinetic potentials were determined using Brookhaven 90Plus/Bi-MAS. The electrophoretic mobility was converted automatically into zeta potential values using the Smoluchowski equation. To generate zeta potential versus $\mathrm{pH}$ curves, $40 \mathrm{mg}$ of sample were dispersed in $40 \mathrm{~mL} \mathrm{KCl} 1 \mathrm{mM}$, used as inert electrolyte. The slurry was continuously stirred and the suspension $\mathrm{pH}$ was adjusted adding $\mathrm{HCl}$ or $\mathrm{KOH}$.

The total specific surface area (TSSA) values of some samples were determined by water vapor adsorption at a relative humidity (rh) of 0.48 as described previously [34]. Also external specific surface area, of Mag sample, was measured by nitrogen adsorption $\left(\mathrm{S}_{\mathrm{N} 2}\right)$ at $77 \mathrm{~K}$, previously dried at $100{ }^{\circ} \mathrm{C}$ for $6 \mathrm{~h}$ under high vacuum, using a Micromeritics Accusorb $2100 \mathrm{E}$ instrument

Total organic carbon (TOC) of some samples was determined by TOC-VCPH (Shimadzu) equipment. The unit of solid samples combustion (SSM-5000A) allows determining TOC by difference between total and inorganic carbon. Previous to analyses, samples were dried at $60{ }^{\circ} \mathrm{C}$ for $48 \mathrm{~h}$.

A stock solution of $1.7 \mathrm{mM} \mathrm{Co}^{2+}$ was prepared by adding the correspondent amount of $\mathrm{CoCl}_{2} \cdot 6 \mathrm{H}_{2} \mathrm{O}$ to distilled water. Additional concentrations were obtained by dilution in distilled water. The $\mathrm{Co}^{2+}$ sorption experiments were performed in batch conditions $(8 \mathrm{~mL}$, $\mathrm{pH}=6.5$, contact time $24 \mathrm{~h}, \mathrm{~T}=25^{\circ} \mathrm{C}$, solid/liquid ratio: $1 \mathrm{gL}^{-1}$ ) varying the initial $\mathrm{Co}^{2+}$ concentration $\left(30,50\right.$ and $85 \mathrm{mgL}^{-1}$ ) and the sorbent materials were: Mt, MtMag, O100Mt and O100MtMag. For Mt and $0100 \mathrm{Mt}$ samples, after the indicated contact time, suspensions were centrifuged for $15 \mathrm{~min}$ at $15,000 \mathrm{rpm}$, while for MtMag, and O100MtMag samples a magnetic separation was utilized.

The supernatants were collected and $\mathrm{Co}^{2+}$ concentration was 


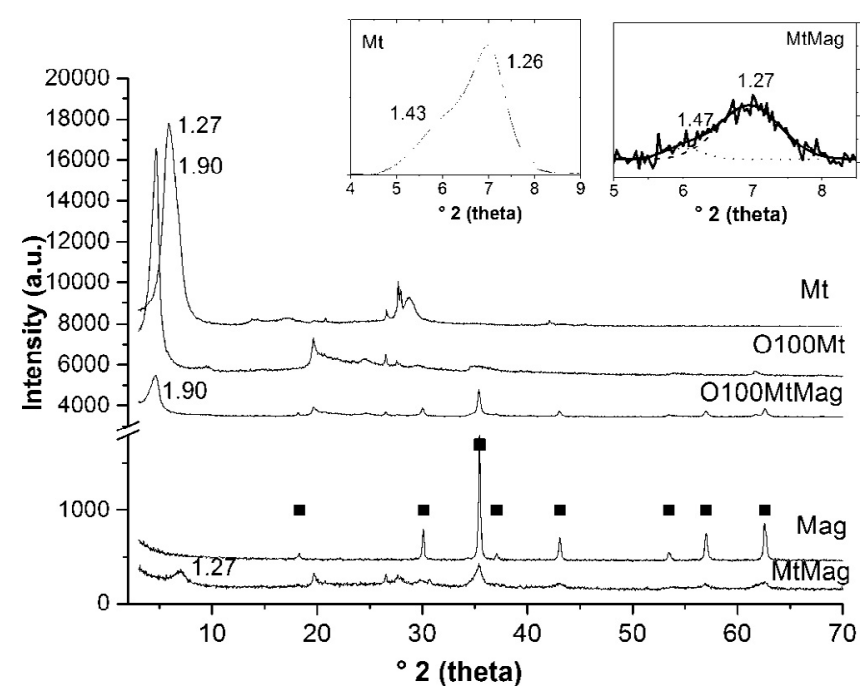

Fig. 1. XRD patterns of Mt, O100Mt, Mag, MtMag and 0100MtMag samples. Symbols: $(\square)$ indicate Mag. Inset: Deconvolution peaks of Mt and MtMag samples. The Mt 001 values are expressed in $\mathrm{nm}$.

determined by colorimetric method [35] using a Hewlett-Packard 8453 UV-visible spectrophotometer (maximum absorption $\lambda=620 \mathrm{~nm}$ ).

\section{Results and discussion}

\subsection{Sample characterization}

X-ray patterns in Fig. 1 show the presence of Mt [36] and, especially in samples with synthetized Mag, the existence of magnetite [37] or goethite [38] can be inferred. The shift of the peak corresponding to the 001 plane of the Mt sample can be assigned to changes in the interlayer space. These changes are useful to following the substitution of the original interlayer cations $\left(\mathrm{Na}^{+}, \mathrm{K}^{+}\right.$and $\mathrm{Ca}^{2+}$ ) by HDTMA ${ }^{+}$. Particularly in the Mt sample, the XRD pattern acquired at a relative humidity of $47 \%$ [39] showed a basal space at $1.27 \mathrm{~nm}$ with a shoulder. Its deconvolution $\left(\mathrm{R}^{2}=0.98\right)$ (Fig. 1 inset), indicates values of the 001 reflection at 1.26 and $1.43 \mathrm{~nm}$, associated to the presence of $\mathrm{Na}^{+}$and $\mathrm{Ca}^{2+}$ at the interlayer respectively, in agreement with the Mt structural formula.

The inclusion of HDTMA ${ }^{+}$ions (O100Mt sample) into the interlayer space of raw Mt generated a shift of the 001 value from 1.27 to $1.90 \mathrm{~nm}$. The interlayer space thicknesses of O100Mt sample, determined from the difference between the 001 value and that of dehydrated Mt $(0.97 \mathrm{~nm})$ [40], of $0.93 \mathrm{~nm}$ indicate a HDTMA ${ }^{+}$arrangement of pseudotrilayer in the Mt interlayer $[16,41]$.

The XRD patterns of Mag reveal the reflections corresponding to $\mathrm{Fe}_{3} \mathrm{O}_{4}$ (magnetite oxide, pdf: 01-088-0315). Due to the limitation found for Fe-bearing phases by XRD (crystalline phases above $\sim 50 \mathrm{~nm}$ in size) with respect to Mössbauer spectroscopy (grain size $<50 \mathrm{~nm}$ even with poor crystallinity) [42], the presence of other iron oxides cannot be neglected. This will be stated more precisely in the following Mössbauer spectroscopy section.

The MtMag sample displays the main peaks of two crystalline components, Mt and iron oxides (Fig. 1). Particularly, the 001 peak of montmorillonite remains constant in MtMag with respect to that of the Mt sample, although a significant loss of intensity and widening (from FWHM $1.6 \pm 0.1$ to $2.9 \pm 0.6 \mathrm{~nm}$ ) is observed. In order to evaluate whether the loss of intensity of the 001 peak is produced by some amorphization created during the synthesis or is the result of the X-ray relative intensities which takes the most intense reflection of all components as $100 \%$, a mechanical mixture of Mt + Mag $(70: 30 \mathrm{w} / \mathrm{w})$ was X-rayed. Like in the MtMag sample, the XRD of the Mt + Mag mixture exhibits the main peaks of Mt and Mag samples (Fig. S1 in Supporting Information). Notwithstanding, some amorphization cannot be ruled out because of the nonlinear base line found for MtMag between 20 and

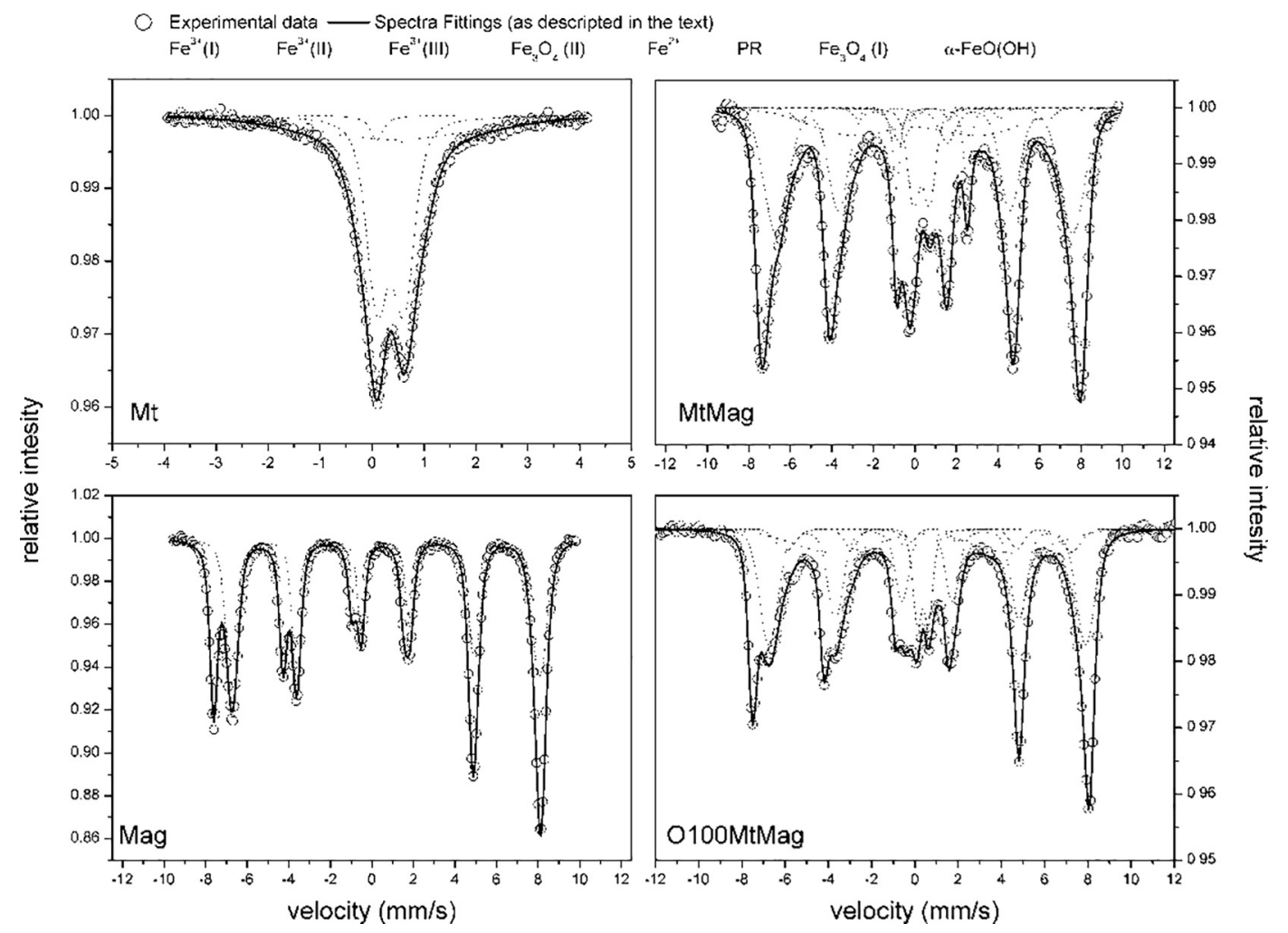

Fig. 2. Room-temperature Mössbauer spectra for the samples of the labels. Open circles are the experimental data. The full lines are the spectra fitted as described in the text. The thinner dashed lines are the hyperfine components used in the fittings. 
Table 1

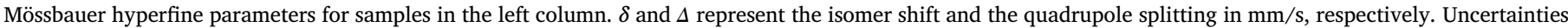

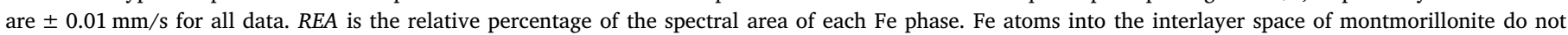
produce a signal in the Mössbauer spectrum [45].

\begin{tabular}{|c|c|c|c|c|c|c|c|c|c|c|c|c|c|c|c|}
\hline \multirow[t]{2}{*}{ Sample } & \multicolumn{3}{|c|}{$\mathrm{Fe}^{3+}(\mathrm{I})$} & \multicolumn{3}{|c|}{$\mathrm{Fe}^{3+}(\mathrm{II})$} & \multicolumn{3}{|c|}{$\mathrm{Fe}^{3+}(\mathrm{III})$} & \multicolumn{3}{|c|}{ Paramagnetic relaxation } & \multicolumn{3}{|l|}{$\mathrm{Fe}^{2+}$} \\
\hline & $\delta$ & $\Delta$ & $R E A$ & $\delta$ & $\Delta$ & $R E A$ & $\delta$ & $\Delta$ & $R E A$ & $\delta$ & $\Delta$ & $R E A$ & $\delta$ & $\Delta$ & $R E A$ \\
\hline Mt/O100Mt & 0.36 & 0.51 & $53 \pm 3$ & 0.37 & 1.15 & $22 \pm 2$ & 0.095 & 0.01 & $3 \pm 1$ & 0.45 & 0.018 & $22 \pm 2$ & - & - & - \\
\hline Mag & - & - & - & - & - & - & - & - & - & - & - & - & - & - & - \\
\hline MtMag & 0.33 & 0.78 & $8 \pm 1$ & 0.59 & 1.82 & $6 \pm 1$ & 0.095 & 0.01 & $<1$ & 0.03 & 6.06 & $14 \pm 2$ & 0.82 & 3.41 & $4 \pm 1$ \\
\hline O100MtMag & 0.37 & 0.52 & $8 \pm 1$ & 0.37 & 1.36 & $3 \pm 1$ & 0.13 & 0.01 & $<1$ & 0.43 & 8.24 & $16 \pm 2$ & - & - & - \\
\hline
\end{tabular}

$30^{\circ}$ (20) compared to that of the Mt + Mag mixture. The broader widening of the 001 peak of montmorillonite, found for MtMag with respect to same peak for the Mt sample encourage performing a peak deconvolution (Fig. 1 inset) to infer the components. Two peaks at 1.47 and $1.27 \mathrm{~nm}$ were found for MtMag. The comparison of both peaks for MtMag with those of Mt, indicates an area decrease of the peaks at $1.47 \mathrm{~nm}$, that could be assigned to the loss of $\mathrm{Ca}^{2+}$, and that at $1.27 \mathrm{~nm}$, associated to the loss of $\mathrm{Na}^{+}$or $\mathrm{K}^{+}$interlayer exchanged during the synthesis process of the magnetic component. Besides, the deconvolution results of MtMag indicate a higher area increase of peak at $1.27 \mathrm{~nm}$ with respect to peak at $1.47 \mathrm{~nm}$ that can be ascribed to an iron interlayer exchange with the initial cations [43]. These latter hypotheses will be discussed in further sections.

The d001 peak reflection of O100MtMag sample did not differ from that of O100Mt sample, while a strong decrease of the intensity was found due to the presence of magnetic material.

Mössbauer spectra were collected to better identify the species in the synthetized samples. Fig. 2 shows the Mössbauer spectra for Mt, Mag, MtMag and O100MtMag samples. Table 1 exhibits the hyperfine parameters and the relative spectral area for each Fe site.

The fittings of Mt and O100Mt (whose spectrum is not shown in Fig. 2) require four Fe sites: three corresponding to $\mathrm{Fe}^{3+}$ doublets and one to paramagnetic relaxation. The $\mathrm{Fe}^{3+}$ sites agree with data reported for montmorillonites coming from Wyoming and Husband mines (Mississippi). The $\mathrm{Fe}^{3+}(\mathrm{I}), \mathrm{Fe}^{3+}$ (II) and $\mathrm{Fe}^{3+}$ (III) were assigned to inner-octahedral, outer-octahedral and tetrahedral $\mathrm{Fe}^{3+}$ doublets, respectively [44]. A paramagnetic relaxation component was necessary to take into account the signal originated in the relaxing Fe ions, which is common in Mt samples with relatively low Fe content, as the Argentine Mt (3.32\% Fe) [45].

The Mössbauer spectrum of Mag sample was fitted to two magnetic Fe environments (Table 2) whose hyperfine parameters correspond to magnetite [46]. Neither hematite nor goethite exists in the Mag sample, in agreement with XRD patterns.

As can be seen from Fig. 2 and Table 1, the Mössbauer spectra of MtMag and O100MtMag reveal, in addition to the four sites observed for Mt, the presence of three magnetic sites (Table 2), two assigned to magnetite [46] and one to goethite [47]. These samples did not show any hematite presence. Furthermore, MtMag also showed a $\mathrm{Fe}^{2+}$ environment, related to the sample treatment [45].
The magnetic properties of the samples reveal if the samples can be isolated from the suspension by an external magnet. Fig. 3 exhibits the magnetization hysteresis curves for the samples Mt/O100Mt, Mag, MtMag and 0100MtMag. Table 3 displays the parameters extracted from the hysteresis loops. The magnetization curves of O100Mt and that of Mt are coincident. The experimental points superposition of Mt and O100Mt samples (Fig. 3) evidenced that the HDMTA inclusion does not affect the magnetic properties of Mt.

The $\chi_{\text {hifi }}$ values displayed in Table 3 may indicate the existence of particles with superparamagnetic or other magnetic regimes.

The saturation magnetization, $M s$ is related to the attraction capacity by a magnet. Mag revels a $M s$ equal to $76.5 \pm 0.1 \mathrm{Am}^{2} \mathrm{~kg}^{-1}$, higher than the one obtained for the pure magnetite synthetized by [48] $\left(28.55 \mathrm{Am}^{2} \mathrm{~kg}^{-1}\right)$. The MtMag and 0100MtMag samples attain $M s$ values of $8.5 \pm 0.1$ and $20.3 \pm 0.1 \mathrm{Am}^{2} / \mathrm{kg}$, respectively, lower than the $M s$ value determined for the Mag sample, which would indicate a lower magnetic mineral concentration [49].

Saturation Magnetization of O100MtMag resulted higher than Ms of MtMag. As discussed in XRD analysis, over the synthesis of MtMag, part of the $\mathrm{Ca}^{2+}$ or $\mathrm{Na}^{+}$ions existing in the montmorillonite interlayer space were exchanged with Fe ions. However, the situation is different when synthesizing O100MtMag because the presence of HDTMA in the clay interlayer likely precludes the inclusion of $\mathrm{Fe}$ in that space. Therefore, over the synthesis of O100MtMag more Fe ions might contribute to the formation of magnetite thus increasing the saturation magnetization of the sample O100MtMag relative to MtMag.

The signals of the Mössbauer spectra of O100MtMag and MtMag assigned to magnetite have similar areas (Table 2). To explain this fact, it should be noticed that, as mentioned by Murad and Cashion [45] Fe ions in the interlayer space of Mt do not show recoil-free absorption of gamma rays at room temperature. Therefore, despite both systems have similar Fe concentration, as yielded by EDS results, the number of resonant Fe atoms of O100MtMag is higher than MtMag. Then the specific magnetite concentration -which is not revealed by Mössbauer- of the O100Mtmag sample, is higher than for MtMag.

The $M r / M s$ rate, indicator of non-uniform magnetic states within an agglomerate, reveal that $\mathrm{Fe}_{3} \mathrm{O}_{4}$ may be fairly uniformly dispersed in the MtMag and O100MtMag samples, since both rates are lower than 0.5 [48].

Table 4 shows the clay mineral elemental composition, obtained by

Table 2

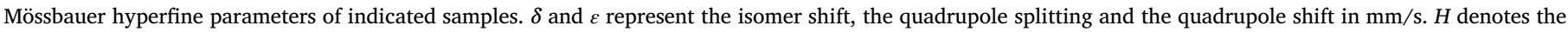

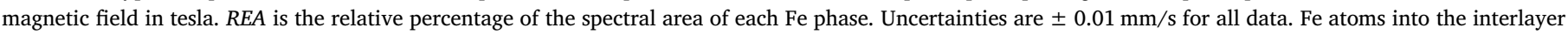
space of montmorillonite do not produce a signal in the Mössbauer spectrum [45].

\begin{tabular}{|c|c|c|c|c|c|c|c|c|c|c|}
\hline \multirow[t]{2}{*}{ Sample } & \multicolumn{3}{|c|}{ Magnetite (I) } & \multicolumn{3}{|c|}{ Magnetite (II) } & \multicolumn{4}{|c|}{ Goethite } \\
\hline & $\delta$ & $H$ & REA & $\delta$ & $H$ & $R E A$ & $\delta$ & $\varepsilon$ & $H$ & $R E A$ \\
\hline Mt/O100Mt & - & - & - & - & - & - & - & - & - & - \\
\hline Mag & 0.28 & 48.8 & $43 \pm 4$ & 0.66 & 45.9 & $57 \pm 5$ & - & - & - & - \\
\hline MtMag & 0.32 & 47.7 & $30 \pm 3$ & 0.45 & 44.3 & $35 \pm 3$ & 0.53 & -0.13 & 36.9 & $3 \pm 1$ \\
\hline O100MtMag & 0.29 & 48.3 & $26 \pm 3$ & 0.57 & 45.4 & $40 \pm 5$ & 0.76 & -0.13 & 41.0 & $7 \pm 1$ \\
\hline
\end{tabular}




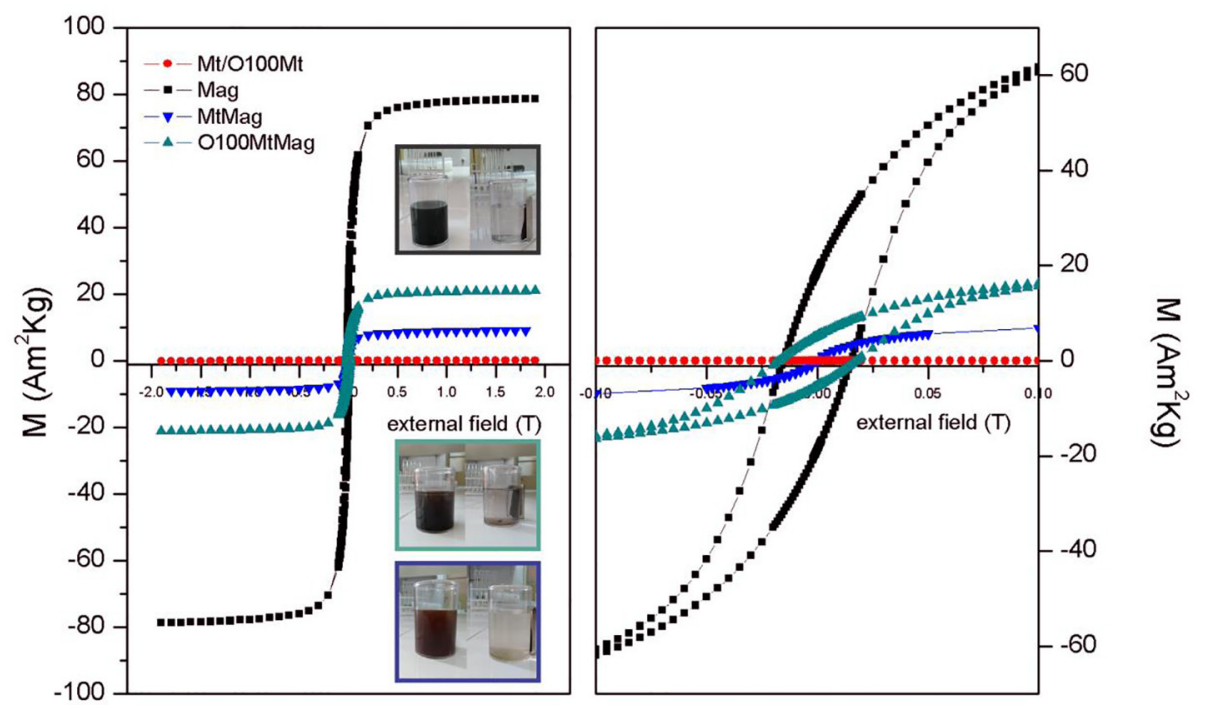

Fig. 3. Total (left) magnetization hysteresis curves for Mt/O100Mt, Mag, MtMag and O100MtMag samples, and (right) the central part of the hysteresis loops.

Table 3

High field magnetization $\left(\chi_{h i f i}\right)$, remanent magnetization $(M r)$ and saturation magnetization $(M s)$ for indicated samples.

\begin{tabular}{llll}
\hline Sample & $\chi_{\text {hifi }}\left(10^{-8} \mathrm{~m}^{3} \mathrm{~kg}^{-1}\right)$ & $M s\left(\mathrm{Am}^{2} \mathrm{~kg}^{-1}\right)$ & $M r\left(\mathrm{Am}^{2} \mathrm{~kg}^{-1}\right)$ \\
\hline Mt & $9.68 \pm 0.02$ & $0.0018 \pm 0.0001$ & $0.00035 \pm 0.00001$ \\
O100Mt & $9.68 \pm 0.02$ & $0.0018 \pm 0.0001$ & $0.00035 \pm 0.00001$ \\
Mag & $150 \pm 9$ & $76.5 \pm 0.1$ & $18.8 \pm 0.5$ \\
MtMag & $54 \pm 3$ & $8.5 \pm 0.1$ & $0.21 \pm 0.02$ \\
O100MtMag & $54 \pm 3$ & $20.3 \pm 0.1$ & $5.2 \pm 0.5$ \\
\hline
\end{tabular}

EDS. The oxides percentage found by EDS for Mt is close to that typically determined in a previous work by chemical analysis, for a sample of the same origin [28].

The MtMag sample shows an important increase of iron and potassium concentration, while the sodium and calcium amounts decrease significantly. Particularly, the potassium amount increase originates in the magnetite synthesis components. It is important to point out that the potassium \% found in the O100MtMag sample is in the same order than that found for the Mt sample, and could be assigned to electrostatic repulsion of the $\mathrm{HDMTA}^{+}$presence.

As a first approach, the decrease of the concentration of the original interlayer cations $\left(\mathrm{Na}^{+}\right.$and $\left.\mathrm{Ca}^{2+}\right)$ in the presence of iron cations, agrees with the previous hypothesis which attribute the changes in the interlayer space to the inclusion of iron during the magnetite synthesis (see Fig. 1). The large amount of $\mathrm{K}^{+}$found in MtMag sample (around $700 \%$ CEC, Table 4) generates a competition for $\mathrm{Fe}^{2+}$ to be attached at the negative sites of the interlayer.

In the O100Mt sample, the carbon amount was not measured due to the interference of the carbon tape used to fix the sample to the sample holder, while interlayer cations $\left(\mathrm{Ca}^{2+}, \mathrm{Na}^{+}\right.$and $\left.\mathrm{K}^{+}\right)$disappeared by the HDTMA $^{+}$exchange [50]. In particular, the lower potassium amount found in the O100MtMag sample with respect to MtMag indicates the inability of $\mathrm{K}^{+}$to replace HDTMA ${ }^{+}$at the interlayer, despite the high amount retained from the synthesis in the MtMag sample. The $\mathrm{SiO}_{2}$ and $\mathrm{Al}_{2} \mathrm{O}_{3} \%$ amounts decrease in the O100Mt sample, which points to the HDTMA ${ }^{+}$covering the Mt surface. Similarly, the $\mathrm{SiO}_{2}$ and $\mathrm{Al}_{2} \mathrm{O}_{3} \%$ decrease in MtMag and O100MtMag samples in relation to Mt and O100Mt samples would indicate the iron oxide (indicated as $\mathrm{Fe}_{2} \mathrm{O}_{3}$ in Table 4) surface coverage. The total amount of iron oxide, indicated as $\mathrm{Fe}_{2} \mathrm{O}_{3}$, increase of $4 \%$ in O100MtMag with respect to MtMag sample.

The morphologies of Mt, MtMag, O100Mt, O100MtMag and synthesized Mag samples have been analyzed by SEM. The micrograph of Mt was used for morphology comparison (Fig. 4a), where the sheet shaped particles showed the typical face-to-edge contact with random orientation, and a uniform size of around $1 \mu \mathrm{m}$ could be estimated. For O100Mt (Fig. 4b), the particles became loose and curly.

The Mag sample can be observed in Fig. 4e, with characteristic rhombic structure of magnetite and particle size distribution with diameters ranging between 60 and $90 \mathrm{~nm}$ with a mean value of $75 \mathrm{~nm}$ [51]. It is apparent that there are particles with lower size, but these particles have not been considered in the statistical analysis due to the difficulty to determine their size because their edge is too diffuse. Therefore, the histogram, as well as those shown in the insets of Fig. 4c and $\mathrm{d}$, should be considered as approximate estimates of the particle size distributions.

Fig. $4 \mathrm{c}$ and d, show details of the MtMag and O100MtMag samples, respectively, where the lower size of the magnetite particles (of around 30 and $60 \mathrm{~nm}$ ) relative to those of the Mag sample can be observed. The difference in the magnetite particle sizes can also be found by comparing the magnetite particle-size distributions of MtMag and O100MtMag (inset in Fig. 4c and d, respectively); mean values of 35 and $45 \mathrm{~nm}$ were calculated. The magnetite particles partially covered both Mt and O100Mt supporting particles. These results agree with the $\mathrm{Mr} / \mathrm{Ms}$ rate values, which also suggest a partial covering of the Mt and O100Mt particles by magnetite (Table 3), albeit the presence of some aggregates [27]. Besides, some amorphization of the rhombic structure of magnetite found in the Mag sample can be observed in magnetite

Table 4

Oxides content of indicated samples determined by EDS expressed as percentage.

\begin{tabular}{|c|c|c|c|c|c|c|c|}
\hline & $\mathrm{SiO}_{2}$ & $\mathrm{Al}_{2} \mathrm{O}_{3}$ & $\mathrm{Fe}_{2} \mathrm{O}_{3}$ & $\mathrm{MgO}$ & $\mathrm{Na}_{2} \mathrm{O}$ & $\mathrm{CaO}$ & $\mathrm{K}_{2} \mathrm{O}$ \\
\hline Mt & $65.0 \pm 0.5$ & $19.2 \pm 0.4$ & $7.8 \pm 0.5$ & $3.4 \pm 0.2$ & $3.6 \pm 0.3$ & $0.5 \pm 0.2$ & $0.6 \pm 0.1$ \\
\hline MtMag & $37.2 \pm 0.5$ & $11.7 \pm 0.3$ & $33.4 \pm 0.6$ & $1.8 \pm 0.2$ & $1.0 \pm 0.2$ & $0.3 \pm 0.2$ & $14.0 \pm 0.4$ \\
\hline O100Mt & $54.2 \pm 3.1$ & $15.4 \pm 1.3$ & $6.0 \pm 0.5$ & $2.5 \pm 0.3$ & 0 & 0 & 0 \\
\hline O100MtMag & $42.4 \pm 1.5$ & $12.9 \pm 0.3$ & $37.0 \pm 0.9$ & $2.3 \pm 0.3$ & 0 & 0 & $0.8 \pm 0.2$ \\
\hline
\end{tabular}



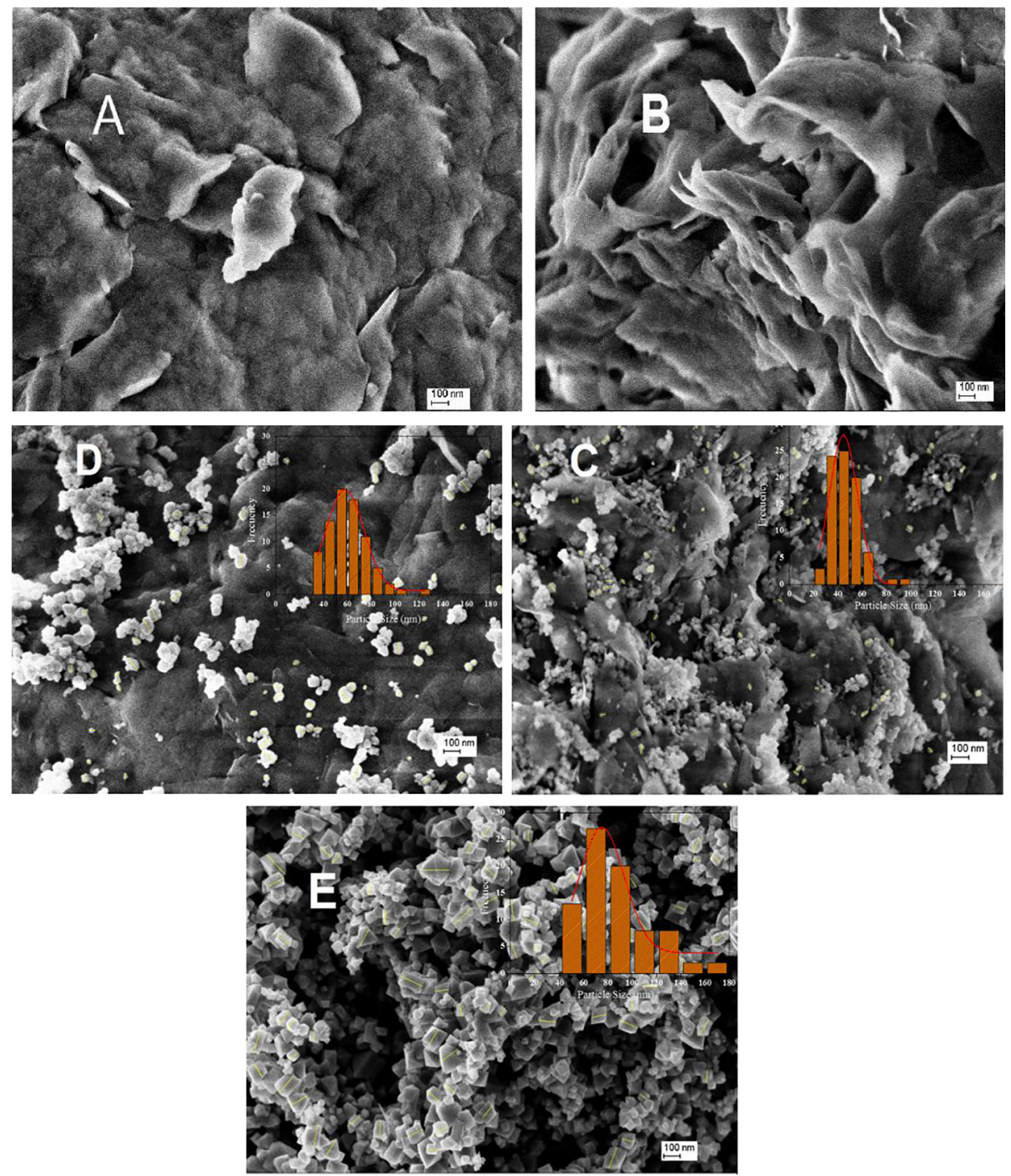

Fig. 4. SEM images of (A) Mt, (B) O100Mt, (C) MtMag, (D) O100MgMt and (E) Mag samples. Insets indicated the respective magnetite particle size distribution.

particles growth on the MtMag and O100MtMag samples, as was inferred by the XRD patterns (Fig. 1 and Fig. S1 in Supporting information).

Summing up, these results indicated that the surface structure of Mt and O100Mt samples demonstrate an obvious change after the magnetite synthesis.

The zeta potential vs $\mathrm{pH}$ curves for Mt, Mag, MtMag, O100Mt and O100MtMag samples and also a Mt + Mag mixture 70:30 (w/w) displayed in (Fig. 5) were carried out to evaluate changes of electrical surface charge between the samples.

The negative zeta potential (around $-40 \mathrm{mV}$ ) observed at all $\mathrm{pH}$ studied for Mt sample is assigned to the predominance of the negative charges on the particle faces with respect to the positive charge coming from the edges [52,53].

For the Mag sample, the $\mathrm{pH}$ dependence of the sign of the zeta potential allowed to determine its zero point of charge (PZC) at around $\mathrm{pH}=6.7$, in agreement with the results reported by [54].

For O100Mt sample the HDTMA cations loading reverse the Mt electric negative charge surface, attaining a positive electric surface charge at around $30-50 \mathrm{mV}$ in all $\mathrm{pH}$ range [16].

The magnetite synthesis seems to modify the electric surface charges of Mt and O100Mt samples in a different way.

In the studied $\mathrm{pH}$ range, a close negative zeta potential is observed (around $-40 \mathrm{mV}$ ) for MtMag and Mt samples. Three behaviors are

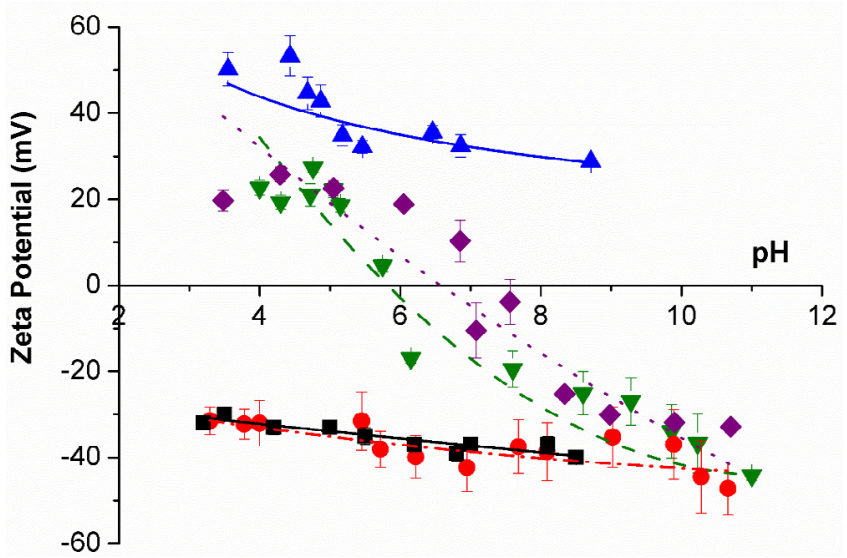

Fig. 5. Zeta Potential vs pH curves. Symbols indicate: $(\square)$ Mt, (•) MtMag, ( $\bullet$ Mag, («) O100Mt and ( $\nabla$ ) O100MtMag samples, and (•) Mt + Mag mixture 70:30.

proposed to rationalize this observation.

First, because the cation exchange at the Mt interlayer does not change its electric charge [55], the cation exchange would generate a zeta potential curve very close to that of the Mt sample [53], but in 
parallel there must be a low or no magnetite sorption at the external surface of the Mt sample. Since this latter behavior contradicts the SEM observation (Fig. 4c), this first hypothesis has been ignored.

A second behavior would consider the full entry of magnetite at the Mt interlayer. Consequently the zeta potential curve of MtMag with respect to that of the Mt sample should not be modified. Notwithstanding, the $\%$ of iron oxide found for MtMag sample (indicated as $\mathrm{Fe}_{2} \mathrm{O}_{3}$ in Table 4) corresponds to more than $20 \times 10^{3}$ the CEC of the Mt sample, and therefore, a significant amount of it must be outside of the Mt interlayer, as shows Fig. 4c. This hypothesis is not fulfilled, and hence other behavior that takes into account the presence of magnetite on the surface of Mt without modifying the surface electrical charge must be reconsidered.

A third behavior would take into account the presence of magnetite on the surface of Mt (Fig. 4c) acting as a mixture of magnetite and Mt particles. This behavior was previously found for soil components [56], which PZC of the mixture related to the surface provided by each component of the mixture [57]. In order to calculate the theoretical PZC of the Mt + Mag mixture the surface and PZC of both particles are needed. For Mt the TSSA $=358.9 \mathrm{~m}^{2} \mathrm{~g}^{-1}$ (determined by water adsorption, in this study) has been used, in order to take into account the interlayer surface [53] and the $\mathrm{PZC}=2.8$ [56]. For magnetite TSSA $=14 \mathrm{~m}^{2} \mathrm{~g}^{-1}$ (determined by water adsorption, in this study, and the specific surface obtained by $\mathrm{N}_{2}$ adsorption was $16.7 \mathrm{~m}^{2} \mathrm{~g}^{-1}$ ) and the PZC $=6.7$ (Fig. 5). As an approach, all iron oxide was considered as magnetite, and from (Table 4) a weight composition of 70:30\% Mt:Mag can be assigned. This ratio changed to $99: 1 \%$ for Mt:Mag when the TSSA values of both components were taken into account. Based on an arithmetic mean sum the mixture PZC would read as follows: $0.99 \times \mathrm{PZC}_{\mathrm{Mt}}+0.01 \times \mathrm{PZC}_{\text {Mag }}=2.84$, value which is in agreement to that of Mt $(\mathrm{PZC}=2.8)$.

In order to confirm this PZC mixture behavior, the zeta potential curve for a Mt:Mag mixture $(70: 30 \mathrm{w} / \mathrm{w})$ was inserted in Fig. 5, which matches the one obtained for MtMag sample. This mixing behavior of zeta potential curve and the SEM image of the MtMag sample (Fig. 4c) discarded the possibility of magnetite presence through a cation exchange in the interlayer of $\mathrm{Mt}$, while the $\mathrm{K}^{+}$exchange cannot be discarded.

Contrary to MtMag, the magnetite loading in O100MtMag generates a similar zeta potential vs $\mathrm{pH}$ curve than Mag, with a PZC close to $\mathrm{pH}=5.8$. The positive and negative surface charges found at basic $\mathrm{pH}$ for $0100 \mathrm{Mt}$ and Mag samples, respectively (Fig. 5), evidenced an electrostatic attraction between both particles. This is in agreement with the higher magnetite coating of the O100MtMag with respect to MtMag samples. Also, a mixture behavior can be ascribed to the calculated PZC $=5.5$ obtained for O100MtMag sample, taking into account the lower TSSA $=84 \mathrm{~m}^{2} \mathrm{~g}^{-1}$ of O100Mt with respect to Mt, and considering again all iron oxide as magnetite (Table 4). Some release of HDTMA $^{+}$from the O100Mt sample surface during the magnetite synthesis cannot be neglected, and also would contribute to the electric surface charge reversal.

In order to evaluate the $\mathrm{HDTMA}^{+}$release from 0100MtMag due to the magnetite loading and also for the further $\mathrm{Co}^{2+}$ sorption (see next section), TOC was evaluated for samples with HDTMA $^{+}$and results were resumed in Table 5.

Table 5

Total Organic Carbon and calculated percentage CEC of HDTMA ${ }^{+}$loading, for indicated samples.

\begin{tabular}{lll}
\hline Sample & TOC $(\mathrm{mg} \mathrm{C} / \mathrm{g}$ clay) & HDTMA loading (\% CEC) \\
\hline O100Mt & $170.6 \pm 5.3$ & 90.7 \\
O100Mt $+\mathrm{Co}^{2+}$ & $157.2 \pm 5.3$ & 83.6 \\
O100MtMag & $129.6 \pm 0.4$ & 68.9 \\
O100MtMag $+\mathrm{Co}^{2+}$ & $128.9 \pm 2.2$ & 68.5 \\
\hline
\end{tabular}

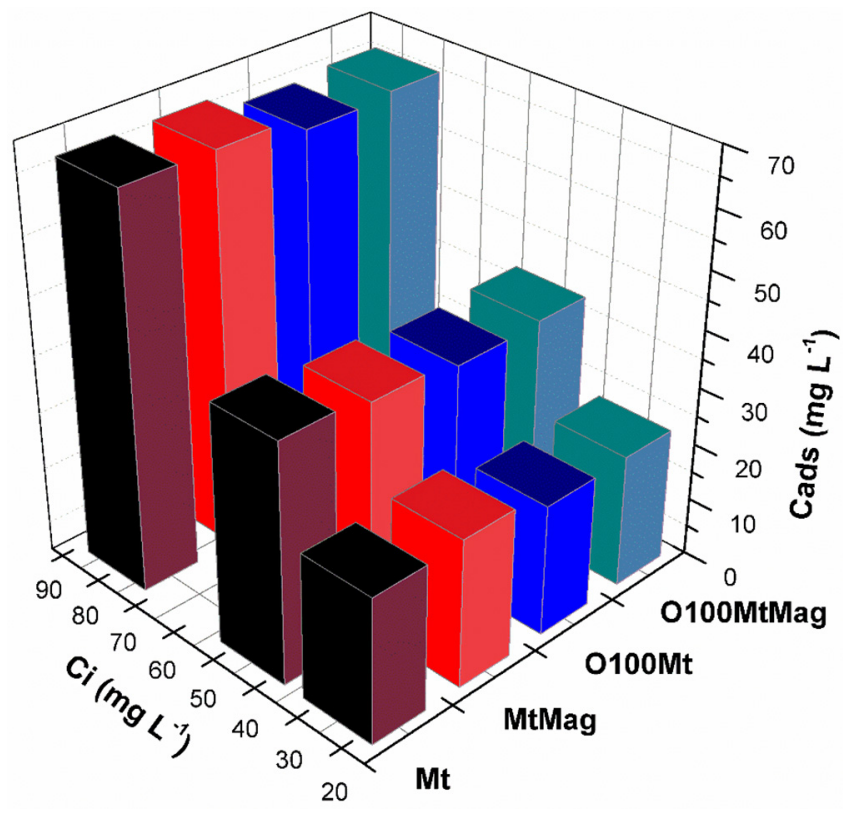

Fig. 6. $\mathrm{Co}^{2+}$ sorption at different $\mathrm{C}_{\mathrm{i}}\left(30,50\right.$ and $\left.85 \mathrm{mg} \mathrm{L}^{-1}\right)$ for the indicated samples. $\quad\left(\mathrm{pH}=6.5\right.$, contact time $24 \mathrm{~h}, \mathrm{~T}=25^{\circ} \mathrm{C}$, and solid/liquid ratio $\left.=1 \mathrm{~g} \mathrm{~L}^{-1}\right)$.

The TOC or HDTMA ${ }^{+}$loading as \% CEC results indicated that $22 \%$ of the initial surfactant was released when magnetite was loaded on the O100Mt sample. Thus the HDTMA ${ }^{+}$loading decrease of $22 \%$ CEC of O100MtMag (Table 5) respect to O100Mt sample, collaborate to decrease its positive electric charges (Fig. 5).

\section{2. $\mathrm{Co}^{2+}$ Sorption}

Fig. 6 shows the effect of three initial concentrations (30, 50 and $85 \mathrm{mg} \mathrm{L}^{-1}$ ) on the $\mathrm{Co}^{2+}$ removal by Mt, MtMag, O100Mt, and O100MtMag samples. There are not significant differences of $\mathrm{Co}^{2+}$ sorbed among samples at the evaluated $\mathrm{Co}^{2+}$ initial concentrations. The $\mathrm{Co}^{2+}$ sorption increase with $\mathrm{C}_{i}$ indicated that surface sites was not saturated up to $\mathrm{C}_{i}=85 \mathrm{mg} \mathrm{L}^{-1}$. The $\mathrm{HDTMA}^{+}$coverage or magnetite mixture seems to not modify the $\mathrm{Co}^{2+}$ sorption respect to Mt sample.

The characterization of samples after $\mathrm{Co}^{2+}$ sorption $\left(C_{i}=85 \mathrm{mg} \mathrm{L}^{-1}\right)$, will help to understand the surface sites involved.

XRD analysis of Mt, MtMag, O100Mt and O100MtMag samples after $\mathrm{Co}^{2+}$ sorption were performed in order to achieve a more complete understanding of the sorption process, by studying changes in the clay interlayer space (Table 6). The $\mathrm{Co}^{2+}$ entry at the Mt interlayer (inner surface) was followed by comparing the 001 value obtained for the same samples without $\mathrm{Co}^{2+}$ sorbed (data from Fig. 2).

A shift of $0.09 \mathrm{~nm}$ for the 001 value (Table 6) revealed that $\mathrm{Co}^{2+}$ was sorbed on the Mt interlayer, assigned to interlayer exchange of $\mathrm{Na}^{+}$ by $\mathrm{Co}^{2+}$ and by formation of outer-sphere complexes at the interlayer

Table 6

Values of 001 peak and zeta potential for indicated samples.

\begin{tabular}{lllll}
\hline & \multicolumn{2}{l}{ Before $\mathrm{Co}^{+2}$ Adsorption } & \multicolumn{2}{l}{ After $\mathrm{Co}^{+2}$ Adsorption } \\
\hline Sample & $\begin{array}{l}\text { Zeta Potential at } \\
\mathrm{pH}=6.5(\mathrm{mV})\end{array}$ & d001 $(\mathrm{nm})$ & $\begin{array}{l}\text { Zeta Potential at } \\
\mathrm{pH}=6.5(\mathrm{mV})\end{array}$ & $\begin{array}{l}\mathrm{d} 001 \\
(\mathrm{~nm})\end{array}$ \\
\hline Mt & -37.0 & $\begin{array}{l}1.49(1.26 ; \\
1.43)\end{array}$ & -25.0 & 1.58 \\
MtMag & -39.0 & $\begin{array}{l}1.27(1.27 ; \\
1.47)\end{array}$ & -29.0 & 1.41 \\
O100Mt & 35.0 & $\begin{array}{l}1.90 \\
1.90\end{array}$ & -10.0 & 1.94 \\
O100MtMag & -17.0 & & & 1.92 \\
\hline
\end{tabular}


permanent-charge sites [58]. This slight shift increased to $0.12 \mathrm{~nm}$ when $\mathrm{Co}^{2+}$ was sorbed on MtMag sample, the absence of $\mathrm{Na}^{+}$(Table 4) would not disregard a slight interlayer entrance of $\mathrm{Co}^{2+}$ as happened in the Mt sample.

Comparable interlayer space values were obtained for both samples with $\mathrm{HDTMA}^{+}$(O100Mt and O100MtMag) without or with $\mathrm{Co}^{2+}$ sorption, but the $\mathrm{Co}^{2+}$ entry cannot be ruled out due to the expansion of the interlayer space thickness produced by the HDTMA ${ }^{+}$presence.

These observations are assigned to the effect that XRD can only provide information on the inclusion of $\mathrm{Co}^{2+}$ cations to the clay interlayer, and it cannot account for differences in $\mathrm{Co}^{2+}$ adsorption at other surface sites or components present. For these reasons, zeta potential determinations have been performed in order to evaluate the electrical external surface charge changes of all samples after $\mathrm{Co}^{2+}$ adsorption.

The zeta potential values at $\mathrm{pH}=6.5$, for $\mathrm{Co}^{2+}\left(\mathrm{C}_{\mathrm{i}}=85 \mathrm{mg} \mathrm{L}^{-1}\right)$ sorbed on Mt, MtMag, O100Mt and O100MtMag, and also values for the same samples without $\mathrm{Co}^{2+}$ (Fig. 5) are summarized in Table 6.

The influence of magnetite on the $\mathrm{Co}^{2+}$ sorption was also evaluated by zeta potential measurements (Fig. S2 in Supporting Information). Comparison of zeta potential curves for Mag sample and Mag with $\mathrm{Co}^{2+}$ sorbed at the same conditions indicated no evident modifications, representing a low or none $\mathrm{Co}^{2+}$ sorption.

The decrease of negative electric net charge of around $10 \mathrm{mV}$ for Mt and MtMag samples after the $\mathrm{Co}^{2+}$ sorption indicated the partial charge neutralization of both external negative charge surfaces by $\mathrm{Co}^{2+}$, due to similar amount of $\mathrm{Co}^{2+}$ adsorbed at both samples (Fig. 6).

The O100Mt sample with $\mathrm{Co}^{2+}$ sorption revealed a significant decrease of the initial positive zeta potential of $45.0 \mathrm{mV}$. This decrease of positive electric charge cannot be assigned to the entry of all $\mathrm{Co}^{2+}$ at the surfactant free Mt interlayer, because changes at the interlayer does not modify the electrical charge, as was indicated previously. The $7.1 \%$ HDTMA $^{+}$release as shown by the TOC determination (Table 5), can partly generate the loss of positive electric charge attained by O100Mt $+\mathrm{Co}^{2+}$ sample. Also some $\mathrm{Co}^{2+}$ interaction with $\mathrm{Br}^{-}$counterion, remnant of the HDTMABr loaded in the O100Mt sample could contribute to decrease the zeta potential of the O100Mt sample with $\mathrm{Co}^{2+}$ sorption. To evaluate the $\mathrm{Co}^{2+}$ and HDTMABr interaction the zeta potential curves were evaluated for two solutions HDTMABr with a concentration above the CMC and a mixture of previous HDTMABr solution and $\mathrm{Co}^{2+}$ with final concentration $=85 \mathrm{mg} \mathrm{L}^{-1}$ (Fig. S3 in Supporting information). A positive electric charge was found for surfactant, due to the micelles generation, above the CMC concentration in all the range of $\mathrm{pH}$ evaluated. However, the decrease of positive charge of the HDTMABr solution in $\mathrm{Co}^{2+}$ presence found (Fig. S3 in Supporting information), allows inferring that a similar behavior occurs in O100Mt sample when $\mathrm{Co}^{2+}$ is present.

The similar loss $(10 \mathrm{mV})$ of negative zeta potential value obtained for O100MtMag than for MtMag after $\mathrm{Co}^{2+}$ adsorption, and the surface of Mt freer of surfactant Mt indicated in Table 5 for O100MtMag with respect to $0100 \mathrm{Mt}$, allows associating a similar behavior to both samples with partial charge neutralization of external negative charge surface.

\section{Conclusion}

This study reveals that the surfaces of Mt and O100Mt samples were successfully modified by Fe oxide, by generation of magnetite and goethite species confirmed by XRD and Mössbauer analyses. The saturation magnetization results, $M s$, reveal a higher magnetite content for the O100MtMag than for the MtMag sample, demonstrating that this material is a better one for external magnets manipulation. The surface electric charge for the MtMag sample exhibits contributions by the mixture of Mag and Mt. Theoretical calculation of the PZC indicates that the Mt/Mag ratio is related to the surface of both components. The similarity of values and shape of zeta potential curve obtained for the
O100MtMag and Mag samples is not produced by the loss of HDTMA but by a greater magnetite coating of $0100 \mathrm{Mt}$, in agreement with the increase of the Ms value. Especially, at basic $\mathrm{pH}$ also an electrostatic attraction between $0100 \mathrm{Mt}$ and magnetite particles can be inferred in the O100MtMag sample.

The four sorbents used were characterized by a strong tendency to adsorb $\mathrm{Co}^{2+}$ in similar amounts without saturation of the surface sites up to initial concentrations of $\mathrm{Co}^{2+}$ of $85 \mathrm{mg} \mathrm{L}^{-1}$. Surface sites involved in the $\mathrm{Co}^{2+}$ sorption are mainly the montmorillonite interlayer and the external surface.

The magnetic modification does not impair the capacity of $\mathrm{Co}^{2+}$ sorption achieved with samples without magnetite, and particularly the O100MtMag sample resulted in the best one for external magnets manipulation.

\section{Acknowledgements}

Financial support of Argentine Ministry of Science, ANPCyT- PICT $585 / 2014$, is gratefully acknowledged. R.M.T.S., M.L. Montes, M. Fernández and R. Candal are members of National Council of Scientific and Technological Research (CONICET) and F. Barraqué acknowledged CONICET fellowships.

\section{Appendix A. Supplementary data}

Supplementary data associated with this article can be found, in the online version, at https://doi.org/10.1016/j.jmmm.2018.07.052.

\section{References}

[1] S. Natesan, C. Ponnusamy, A. Sugumaran, S. Chelladurai, S. Shanmugam Palaniappan, R. Palanichamy, Artemisinin loaded chitosan magnetic nanoparticles for the efficient targeting to the breast cancer, Int. J. Biol. Macromol. 104 (2017) 1853-1859.

[2] C. Santhosh, V. Velmurugan, G. Jacob, S.K. Jeong, A.N. Grace, A. Bhatnagar, Role of nanomaterials in water treatment applications: a review, Chem. Eng. J. 306 (2016) 1116-1137.

[3] C.T. Yavuz, J.T. Mayo, C. Suchecki, J. Wang, A.Z. Ellsworth, H. D'couto, E. Quevedo, A. Prakash, L. Gonzalez, C. Nguyen, C. Kelty, V.L. Colvin, Pollution magnet: nano-magnetite for arsenic removal from drinking water, Environ. Geochem. Health 32 (2010) 327-334.

[4] D.-W. Cho, B.-H. Jeon, C.-M. Chon, Y. Kim, F.W. Schwartz, E.-S. Lee, H. Song, A novel chitosan/clay/magnetite composite for adsorption of $\mathrm{Cu}(\mathrm{II})$ and $\mathrm{As}(\mathrm{V})$, Chem. Eng. J. 200-202 (2012) 654-662.

[5] J.F. Liu, Z.S. Zhao, G.B. Jiang, Coating Fe3O4 magnetic nanoparticles with humic acid for high efficient removal of heavy metals in water, Environ. Sci. Technol. 42 (2008) 6949-6954.

[6] A. Bée, L. Obeid, R. Mbolantenaina, M. Welschbillig, D. Talbot, Magnetic chitosan/ clay beads: a magsorbent for the removal of cationic dye from water, J. Magn. Magn. Mater. 421 (2017) 59-64.

[7] K.R. Kumrić, A.B. Đukić, T.M. Trtić-Petrović, N.S. Vukelić, Z. Stojanović, J.D. Grbović Novaković, L.L. Matović, Simultaneous removal of divalent heavy metals from aqueous solutions using raw and mechanochemically treated interstratified montmorillonite/kaolinite clay, Ind. Eng. Chem. Res. 52 (2013) 7930-7939.

[8] K.G. Bhattacharyya, S.S. Gupta, Adsorption of a few heavy metals on natural and modified kaolinite and montmorillonite: a review, Adv. Colloid Interface Sci. 140 (2008) 114-131.

[9] O. Abollino, M. Aceto, M. Malandrino, C. Sarzanini, E. Mentasti, Adsorption of heavy metals on Na-montmorillonite. Effect of $\mathrm{pH}$ and organic substances, Water Res. 37 (2003) 1619-1627.

[10] T. Ngulube, J.R. Gumbo, V. Masindi, A. Maity, An update on synthetic dyes adsorption onto clay based minerals: a state-of-art review, J. Environ. Manage. 191 (2017) 35-57.

[11] L. Deng, P. Yuan, D. Liu, F. Annabi-Bergaya, J. Zhou, F. Chen, Z. Liu, Effects of microstructure of clay minerals, montmorillonite, kaolinite and halloysite, on their benzene adsorption behaviors, Appl. Clay Sci. 143 (2017) 184-191.

[12] W.H. Yu, N. Li, D.S. Tong, C.H. Zhou, C.X. Lin, C.Y. Xu, Adsorption of proteins and nucleic acids on clay minerals and their interactions: a review, Appl. Clay Sci. 80-81 (2013) 443-452.

[13] M. Gamba, P. Kovář, M. Pospíšil, R.M. Torres Sánchez, Insight into thiabendazole interaction with montmorillonite and organically modified montmorillonites, Appl. Clay Sci. 137 (2017) 59-68.

[14] I. Fatimah, T. Huda, Preparation of cetyltrimethylammonium intercalated Indonesian montmorillonite for adsorption of toluene, Appl. Clay Sci. 74 (2013) $115-120$. 
[15] L.F. Lima, J.R. De Andrade, M.G.C. Da Silva, M.G.A. Vieira, Fixed Bed Adsorption of Benzene, Toluene, and Xylene (BTX) Contaminants from Monocomponent and Multicomponent Solutions Using a Commercial Organoclay, Ind. Eng. Chem. Res. 56 (2017) 6326-6336.

[16] A.E. Bianchi, M. Fernández, M. Pantanetti, R. Viña, I. Torriani, R.M.T. Sánchez, G. Punte, ODTMA + and HDTMA + organo-montmorillonites characterization: new insight by WAXS, SAXS and surface charge, Appl. Clay Sci. 83-84 (2013) 280-285.

[17] Q. Wang, L. Peng, G. Li, P. Zhang, D. Li, F. Huang, Q. Wei, Activity of laccase immobilized on TiO2-Montmorillonite Complexes, Int. J. Mol. Sci. 14 (2013) $12520-12532$

[18] H. Pourabolghasem, M. Ghorbanpour, R. Shayegh, Antibacterial activity of copperdoped montmorillonite nanocomposites prepared by alkaline ion exchange method, J. Phys. Sci. 27 (2016) 1-12.

[19] G. Jing, Z. Sun, P. Ye, S. Wei, Y. Liang, Clays for heterogeneous photocatalytic decolorization of wastewaters contaminated with synthetic dyes: a review, Water Pract. Technol. 12 (2017) 432-443.

[20] P. Praus, M. Turicová, M. Karlíková, L. Kvítek, R. Dvorský, Nanocomposite of montmorillonite and silver nanoparticles: characterization and application in catalytic reduction of 4-nitrophenol, Mater. Chem. Phys. 140 (2013) 493-498.

[21] K. Kalantari, M.B. Ahmad, H.R. Fard Masoumi, K. Shameli, M. Basri, R. Khandanlou, Rapid and high capacity adsorption of heavy metals by Fe3O4/montmorillonite nanocomposite using response surface methodology: preparation, characterization, optimization, equilibrium isotherms, and adsorption kinetics study, J. Taiwan Inst. Chem. Eng. 49 (2015) 192-198.

[22] L. Chen, C.H. Zhou, S. Fiore, D.S. Tong, H. Zhang, C.S. Li, S.F. Ji, W.H. Yu, Functional magnetic nanoparticle/clay mineral nanocomposites: preparation, magnetism and versatile applications, Appl. Clay Sci. 127-128 (2016) 143-163.

[23] J. Chang, J. Ma, Q. Ma, D. Zhang, N. Qiao, M. Hu, H. Ma, Adsorption of methylene blue onto Fe3O4/activated montmorillonite nanocomposite, Appl. Clay Sci. 119 (2016) 132-140.

[24] G. Carja, H. Chiriac, N. Lupu, New magnetic organic-inorganic composites based on hydrotalcite-like anionic clays for drug delivery, J. Magn. Magn. Mater. 311 (2007) 26-30.

[25] A.E. Regazzoni, Formation of magnetite (Fe $3 \mathrm{O} 4$ ) in aqueous media and properties of the interface magnetite/solution, Repository I (1984).

[26] I.J. Bruce, J. Taylor, M. Todd, M.J. Davies, E. Borioni, C. Sangregorio, T. Sen, Synthesis, characterisation and application of silica-magnetite nanocomposites, J. Magn. Magn. Mater. 284 (2004) 145-160.

[27] H. Bartonkova, M. Mashlan, I. Medrik, D. Jancik, R. Zboril, Magnetically modified bentonite as a possible contrast agent in MRI of gastrointestinal tract, Chem. Pap. 61 (2007) 413-416.

[28] A.P. Magnoli, L. Tallone, C.A.R. Rosa, A.M. Dalcero, S.M. Chiacchiera, R.M. Torres Sanchez, Commercial bentonites as detoxifier of broiler feed contaminated with aflatoxin, Appl. Clay Sci. 40 (2008) 63-71.

[29] M. Gamba, F.M. Flores, J. Madejová, R.M.T. Sánchez, Comparison of imazalil removal onto montmorillonite and nanomontmorillonite and adsorption surface sites involved: an approach for agricultural wastewater treatment, Ind. Eng. Chem. Res. 54 (2015) 1529-1538.

[30] M. Rosen (Ed.), Surfactants and Interfacial Phenomena, second ed., New York, 1989.

[31] U. Schwertmann, R.M. Cornell (Eds.), Iron Oxides in the Laboratory. Preparation and Characterization, second ed., Wiley-VCH, Germany, 2000.

[32] A. Pacuła, E. Bielańska, A. Gaweł, K. Bahranowski, E.M. Serwicka, Textural effects in powdered montmorillonite induced by freeze-drying and ultrasound pretreatment, Appl. Clay Sci. 32 (2006) 64-72.

[33] K. Lagarec, D.G. Rancourt, Recoil-Mössbauer Spectral Analysis Software for Windows, Version 1, University of Ottawa, Ottawa, 1998.

[34] R.M. Torres Sánchez, Mechanochemical effects on physicochemical parameters of homoionic smectite, Colloids Surf. A Physicochem. Eng. Asp. 127 (1997) 135-140.

[35] E.B. Sandell (Ed.), Colorimetric Determination of Traces of Metals, second ed., Interscience Publishers Inc., New York, 1950.
[36] A. Viani, A.F. Gualtieri, G. Artioli, The nature of disorder in montmorillonite by simulation of X-ray powder patterns, Am. Mineral. 87 (2002) 966-975.

[37] B.A. Wechsler, D.H. Lindsley, C.T. Prewitt, Crystal structure and cation distribution in titanomagnetites (Fe (sub 3-x) Ti x O 4), Am. Mineral. 69 (1984) 754-770.

[38] A.F. Gualtieri, P. Venturelli, In situ study of the goethite-hematite phase transformation by real time synchrotron powder diffraction, Am. Mineral. 84 (1999) 895-904

[39] T. Iwasaki, T. Watanabe, Distribution of Ca and Na ions in dioctahedral smectites and interstratified dioctahedral Mica/Smectites, Clay. Clay Miner. 36 (1988) 73-82.

[40] K. Emmerich, M. Plötze, G. Kahr, Reversible collapse and Mg2 + release of de- and rehydroxylated homoionic cis-vacant montmorillonites, Appl. Clay Sci. 19 (2001) 143-154.

[41] H. He, R.L. Frost, T. Bostrom, P. Yuan, L. Duong, D. Yang, Y. Xi, J.T. Kloprogge, Changes in the morphology of organoclays with HDTMA + surfactant loading, Appl. Clay Sci. 31 (2006) 262-271.

[42] P.A. Bland, G. Cressey, O.N. Menzies, Modal mineralogy of carbonaceous chondrites by X-ray diffraction and Mössbauer spectroscopy, Meteorit. Planet. Sci. 39 (2004) 3-16.

[43] C. Luengo, V. Puccia, M. Avena, Arsenate adsorption and desorption kinetics on a Fe (III)-modified montmorillonite, J. Hazard. Mater. 186 (2011) 1713-1719.

[44] J. Johnston, C. Cardile, Iron substitution in montmorillonite, illite and glauconite by 57 Fe Mossbauer spectroscopy, Clays Clay Miner.. 35 (1987) 170.

[45] E. Murad, J. Cashion, Clay-Sized Phyllosilicates, In Mössbauer spectroscopy of environmental materials and their industrial utilization, Springer Science \& Business Media, New York, 2011, pp. 127-157.

[46] R.E. Vandenberghe, E. De Grave, C. Landuydt, L.H. Bowen, Some aspects con cerning the characterization of iron oxides and hydroxides in soils and clays, Hyperfine Interact 53 (1990) 175-195.

[47] E. Murad, Mössbauer spectroscopy of clays, soils and their mineral constituents, Clay Miner. 45 (2010) 413-430.

[48] H. Chen, Y. Li, S. Wang, Y. Zhou, Synthesis of montmorillonite/Fe3O4-OTAB composite capable of using as anisotropic nanoparticles, Appl. Surf. Sci. 402 (2017) 384-391.

[49] M. Evans, F. Heller (Eds.), Environmental Magnetism: Principles and Applications of Enviromagnetics, Academic press, USA, 2003An imprint of Elsevier Science.

[50] B. Schampera, D. Tunega, R. Šolc, S.K. Woche, R. Mikutta, R. Wirth, S. Dultz, G. Guggenberger, External surface structure of organoclays analyzed by transmission electron microscopy and X-ray photoelectron spectroscopy in combination with molecular dynamics simulations, J. Colloid Interface Sci. 478 (2016) 188-200.

[51] A. Del Campo, T. Sen, J.P. Lellouche, I.J. Bruce, Multifunctional magnetite and silica-magnetite nanoparticles: synthesis, surface activation and applications in life sciences, J. Magn. Magn. Mater. 293 (2005) 33-40.

[52] T. Missana, A. Adell, On the applicability of DLVO theory to the prediction of clay colloids stability, J. Colloid Interface Sci. 230 (2000) 150-156.

[53] M. Fernández, M.D. Alba, R.M. Torres Sánchez, Effects of thermal and mechanical treatments on montmorillonite homoionized with mono- and polyvalent cations: insight into the surface and structural changes, Colloids Surf. A Physicochem. Eng. Asp. 423 (2013) 1-10.

[54] Z.-X. Sun, F.-W. Su, W. Forsling, P.-O. Samskog, Surface characteristics of magnetite in aqueous suspension, J. Colloid Interface Sci. 197 (1998) 151-159.

[55] F. Thomas, L.J. Michot, D. Vantelon, E. Montargès, B. Prélot, M. Cruchaudet, J.F. Delon, Layer charge and electrophoretic mobility of smectites, Colloids Surf. A Physicochem. Eng. Asp. 159 (1999) 351-358.

[56] C. Taubaso, M.D.S. Afonso, R.T. Sánchez, Modelling soil surface charge density using mineral composition, Geoderma 121 (2004) 123-133.

[57] M. Tschapek, C. Wasowki, R.M.T. Sánchez, The PZC of $\mathrm{SiO}_{2}+\mathrm{Al}_{2} \mathrm{O}_{3}$ mixtures, Anales de Edaf. y Agrob. 38 (1979) 589-596.

[58] C. Papelis, K.F. Hayes, Distinguishing between interlayer and external sorption sites of clay minerals using X-ray absorption spectroscopy, Colloids Surf. A Physicochem. Eng. Asp. 107 (1996) 89-96. 